\title{
Do physiological integration and soil heterogeneity influence the clonal growth and foraging of Schoenoplectus pungens?
}

\author{
Allison Poor*, Chad Hershock, Kristin Rosella and Deborah E. Goldberg \\ Department of Ecology and Evolutionary Biology, University of Michigan, Ann Arbor, MI 48109, USA; \\ *Author for correspondence (e-mail: apoor@umich.edu)
}

Received 8 August 2003; accepted in revised form 15 February 2005

Key words: Cyperaceae, Fens, Morphological plasticity, Peatlands, Severing

\begin{abstract}
Physiological integration and foraging behavior have both been proposed as advantages for clonal growth in heterogeneous environments. We tested three predictions concerning their short- and long-term effects on the growth of the clonal perennial sedge Schoenoplectus pungens (Pers.) Volk. ex Schinz and R. Keller: (1) growth would be greatest for clones with connected rhizomes and on heterogeneous soil, (2) clones would preferentially place biomass in the nutrient-rich patches of a spatially heterogeneous environment, and (3) physiological integration would decrease a clone's ability to forage. We tested our predictions by growing S. pungens clones for 2 years in an experimental garden with two severing treatments (connected and severed rhizomes) crossed with two soil treatments (homogeneous and heterogeneous nutrient distribution). Severing treatments were only carried out in the first year. As predicted, severing significantly decreased total biomass and per capita growth rate in year one and individual ramet biomass both in year one and the year after severing stopped. This reduction in growth was most likely caused by severing damage, because the total biomass and growth rate in severed treatments did not vary with soil heterogeneity. Contrary to our prediction, total biomass and number of ramets were highest on homogeneous soil at the end of year two, regardless of severing treatment, possibly because ramets in heterogeneous treatments were initially planted in a nutrient-poor patch. Finally, as predicted, S. pungens concentrated ramets in the nutrient-rich patches of the heterogeneous soil treatment. This foraging behavior seemed enhanced by physiological integration in the first year, but any possible enhancement disappeared the year after severing stopped. It seems that over time, individual ramets become independent, and parent ramets respond independently to the conditions of their local microsite when producing offspring, a life-history pattern that may be the rule for clonal species with the spreading "guerrilla" growth form.
\end{abstract}

\section{Introduction}

In nature, resources are usually not distributed evenly in space, and this environmental heterogeneity presents a challenge to plants that cannot actively move between resource-rich patches. The challenge of resource heterogeneity is met by clonal plants, which we define as those that reproduce asexually by means of genetically identical modular units, called ramets. Physiological integration, the ability to transport resources between ramets, is a property of many rhizomatous and stoloniferous clonal plant species (Slade and Hutchings 1987; Price et al. 1992; D'Hertefeldt and Jónsdóttir 1999; D'Hertefeldt and Falkengren-Grerup 2002) and has been shown to 
provide a growth advantage in heterogeneous habitats (Alpert and Mooney 1986; Evans 1988; Alpert 1991; Evans and Whitney 1992; Stuefer et al. 1994; Wijesinghe and Handel 1994; Dong and Alaten 1999). Two possible explanations have been proposed for this growth advantage. First, ramets in resource-rich patches can specialize in the uptake of abundant resources and export them to ramets in resource-poor patches (Evans 1988; Stuefer et al. 1994; D'Hertefeldt and Jónsdóttir 1999). Specialization for capturing only the most locally abundant resources is more cost-effective than specialization for capturing scarce resources. Such a strategy, known as division of labor, allows the entire clone to maximize its resource uptake efficiency as long as different essential resources are abundant in different patches (Slade and Hutchings 1987; Hutchings and Price 1993; Stuefer et al. 1996). As a result, the clone as a whole is able to grow larger than it would if it grew on homogeneous soil and no specialization occurred. A second advantage of clonal integration in a heterogeneous environment is that newly established ramets in resource-poor microsites can rely on resources transported acropetally from a parent ramet in a resource-rich microsite (Noble and Marshall 1983; Alpert and Mooney 1986; Wijesinghe and Handel 1994). New ramets grow faster and larger in a resource-poor habitat than they would if they had to support themselves (Alpert and Mooney 1986).

Physiological integration is only one potential strategy for coping with environmental heterogeneity; a second is morphological plasticity. Many studies have indicated that clonal plants can increase resource uptake in resource-rich patches by altering their growth patterns (Slade and Hutchings 1987; Sutherland and Stillman 1988; Hutchings and Mogie 1990; Hutchings and Price 1993; Evans and Cain 1995; Dong and Alaten 1999). Foraging tactics are those plastic growth responses that allow a clonal plant to seek out the richest patches of a spatially heterogeneous environment and to invest the greatest proportion of its biomass in those patches (Dong and Alaten 1999). A plant may shorten its rhizomes, increase its branching frequency, change its branching angles, and/or grow larger ramets when it encounters a resource-rich patch (de Kroon and Hutchings 1995; Evans and Cain 1995; Wijesinghe and Hutchings 1997, 1999; Dong and Alaten
1999). On the other hand, in a resource-poor patch, a plant may adopt a linear morphology, lengthening its rhizomes and branching less frequently to 'escape' the bad patch (Slade and Hutchings 1987; Evans 1988; de Kroon and Schieving 1990; Hutchings and Moogie 1990; Evans and Cain 1995). An alternative plastic foraging scenario exists in which a clone increases the length of its rhizomes where it encounters a resource-rich patch, placing more ramets outside of the patch. This type of response has been thought to benefit the plant when too many ramets in one area threaten to deplete resources too soon (Jerling 1988; Sutherland and Stillman 1988; de Kroon and Schieving 1990). This type of tactic also would increase the clone's chances of encountering more resource-rich patches scattered over a wider area (Jerling 1988; de Kroon and Schieving 1990).

Although many studies have investigated the effects of physiological integration and of foraging on clonal plant fitness in heterogeneous environments, few have investigated potential interactions between these two features of clonality. D'Hertefeldt and Jónsdóttir (1999) have suggested that integration allows clonal plants to buffer against the effects of habitat heterogeneity, because ramets in resource-rich patches have the potential to provide excess resources to ramets in resource-poor patches. As long as some ramets fell in resource-rich patches, the clone would receive all of the resources it needed. In this scenario, plastic growth would be unnecessary, and even costly, if the resource distribution were temporally unpredictable (Hutchings and de Kroon 1994). Overall, ramets would be equal in size and evenly distributed, as concentrating biomass in a particular area would be disastrous if the environment suddenly changed. However, ramet level foraging - that is, the plastic growth responses of individual ramets - would still be expected, in fitting with a division of labor scheme.

The opposite situation, in which integration increases the foraging response of clonal plants, has been little studied. It seems feasible that the establishment and proliferation of ramets in resource-rich patches could be controlled by the amount of resources available for import from the rest of the clone. Instead of buffering against environmental heterogeneity, this situation would result in concentration of biomass in certain high 
quality sites. Alpert (1999) found that clonal fragments showed more plasticity in growth when connected than when severed, and plasticity is, by definition, necessary for foraging behavior (de Kroon and Hutchings 1995). Wijesinghe and Handel (1994) found that the stolons of severed clones grew shorter and produced fewer ramets than those of intact clones. In a heterogeneous environment with widely scattered patches of nutrients, this would make clones less able to escape from unfavorable sites and then concentrate ramets in favorable sites, particularly in environments where seedling recruitment is rare (e.g. fens, tundra).

Additionally, few studies have examined the long-term (i.e., more than one growing season) effects of physiological integration. It is known that connections between ramets in the genus Carex can remain functional for several years (D’Hertefeldt and Jónsdóttir 1999). Some have suggested that these long-lived connections function in the mobilization of stored resources and therefore contribute positively to the growth of subsequent ramet generations (Charpentier et al. 1998; D’Hertefeldt and Jónsdóttir 1999). Physiological integration may also play a role in apical dominance over axillary buds, and thus control ramet density (Charpentier et al. 1998).

To investigate the potential short- and longterm benefits of integration and foraging behavior in clonal plants, we examined the first- and secondyear growth of Schoenoplectus pungens (Pers.) Volk. ex Schinz and R. Keller clones after either severing or leaving their rhizomes connected in the first year and growing the clones on either heterogeneous or homogeneous soil in an experimental garden in southeastern Michigan. We asked the following questions: (1) What is the long-term effect of physiological integration on the growth of $S$. pungens in a heterogeneous environment relative to a homogeneous environment? We predicted that clones with intact rhizomes would grow more than clones with severed rhizomes, and that this effect would be greatest in a heterogeneous environment. (2) Does $S$. pungens exhibit plastic foraging behavior in a heterogeneous environment? We predicted that it would, and that this would result in the preferential placement of biomass in the nutrient-rich patches, whereas biomass in the homogeneous environment would be evenly distributed. (3) If $S$. pungens is able to forage, how is this ability affected by physiological integration? We predicted that integration would decrease the foraging response by allowing clones to buffer against heterogeneity.

\section{Materials and methods}

\section{Species}

Schoenoplectus pungens is a clonal perennial sedge native throughout the United States and southern Canada (Magee 1981). S. pungens propagates itself asexually by means of long, thick underground rhizomes that may persist for several years (Charpentier et al. 1998). Individual ramets are spaced relatively far apart on the rhizomes (mean $\pm 95 \%$ CI for 101 ramets $=3.5 \pm 0.9 \mathrm{~cm}$, Hershock, unpublished data), giving the clone a 'guerilla' morphology (Lovett Doust 1981; de Kroon and van Groenendael 1997). The clone's above-ground shoots persist from June until August in Michigan. In the fall they die, leaving the underground rhizomes to overwinter. $S$. pungens is found on sandy, gravelly, marly or peaty soils of fens, marshes, and lake margins, sometimes in up to two and a half feet of standing water (Voss 1972). In Michigan, it often grows in calcareous fens, wetlands characterized by a ground water source, circumneutral $\mathrm{pH}$, and at least 30-40 cm of organic soil (Amon et al. 2002; Hershock 2002). The fen habitat provides an excellent opportunity to study plant responses to environmental heterogeneity, because precipitation of calcite at the fen surface creates patches of nutrient-poor marl soil (in one study, 15\% organic matter; $\mathrm{pH}=7 ; \mathrm{N}$ mineralization rate $=0.1 \mu \mathrm{g}$ $\mathrm{N} / \mathrm{g}$ dry soil/day; $[\mathrm{Ca}]=744 \mu \mathrm{g} \mathrm{Ca} / \mathrm{g}$ dry soil; $[\mathrm{P}]=17 \mu \mathrm{g} \mathrm{P} / \mathrm{g}$ dry soil) interspersed among patches of peaty, nutrient-rich soil $(74 \%$ organic matter; $\mathrm{pH}=6 ; \mathrm{N}$ mineralization rate $=1.3 \mu \mathrm{g}$ $\mathrm{N} / \mathrm{g}$ dry soil/day; $[\mathrm{Ca}]=1239 \mu \mathrm{g} \mathrm{Ca} / \mathrm{g}$ dry soil; $[\mathrm{P}]=34 \mu \mathrm{g} \mathrm{P} / \mathrm{g}$ dry soil) (Hershock 2002).

\section{Experimental Design}

We tested our hypotheses using fen mesocosms in an outdoor experimental garden at the University of Michigan Matthaei Botanical Gardens, Ann 
Arbor, MI, USA $\left(42^{\circ} 20^{\prime} \mathrm{N}, 83^{\circ} 36^{\prime} \mathrm{W}\right)$. To recreate a fen environment within each mesocosm, we used marl and peat soils that were commercially harvested from Michigan fens and an irrigation system that supplied water from the same ground water source that feeds a natural fen at the Botanical Gardens. Soils were not screened or treated in any way during harvest. The mesocosms consisted of 20 polyethylene tubs $40 \mathrm{~cm}$ high $\times 46 \mathrm{~cm}$ wide $\times 65 \mathrm{~cm}$ long that we arranged into five experimental blocks of four tubs each.

Each mesocosm was initially planted with a single ramet on June 25, 2001. We collected the ramets from clones grown in on-site 'sedge farms', which consisted of ramets that were collected in 1998 from field sites in southeastern Michigan and propagated clonally in plastic tubs. For this experiment, ramets were taken from clones consisting of at least eight ramets, and they were cut so that at least $1 \mathrm{~cm}$ of rhizome was left intact on either side. We only used undamaged ramets with shoots taller than $10 \mathrm{~cm}$. After isolating a ramet, we removed all buds remaining on the rhizome to reduce any subsequent variability in branching frequency. We avoided damaging the roots as much as possible. We planted each ramet in the center of a tub at a depth of $6 \mathrm{~cm}$ and oriented them so that the rhizome growing direction was west. The tubs in each block contained ramets from the same clone, thus eliminating any genetic variability within an experimental block.

Throughout the experiment, plants were watered continuously with a drip irrigation system that delivered water to each tub at a constant rate of $1.9 \mathrm{l} \mathrm{h}^{-1}$. Three holes were drilled into two sides of each tub to serve as drainage. We also turned off the irrigation system as needed to keep water at a constant level just below the soil surface.

To investigate the effects of soil heterogeneity, we created two soil treatments: marl and peat mixed homogeneously and marl and peat distributed patchily. In both treatments, marl soil was used as a nutrient-poor substrate and peat soil was used as a nutrient-rich substrate (Hershock 2002). To create the homogeneous soil treatment, we thoroughly combined $80 \%$ marl and $20 \%$ peat. The patchy soil treatment contained these same total proportions of marl and peat, to ensure that clones grown on homogeneous and patchy soil had access to the same total amount of nutrients. However, for the patchy treatment we inserted wooden frames into the tubs to mark off two patches for peat soil (Figure 1). Marl soil was filled in around the blocks and peat soil was added to the interior of the patches, resulting in two nutrient-rich peat bands traversing the width of the tub (Figure 1). We then removed the frames and leveled off the soil $5 \mathrm{~cm}$ below the top of the tub.

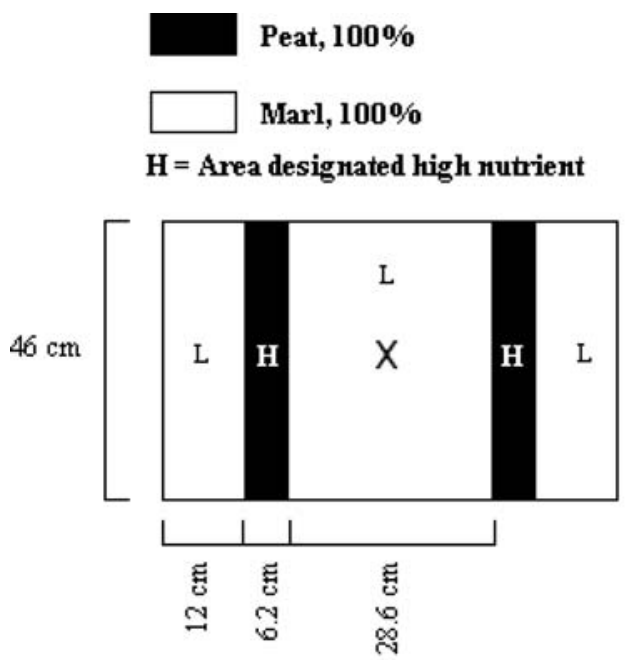

Patchy soil treatment
Peat, 20\%; Marl, 80\%

\section{$X \quad$ Location of original ramet}

$\mathbf{L}=$ Area designated low nutrient

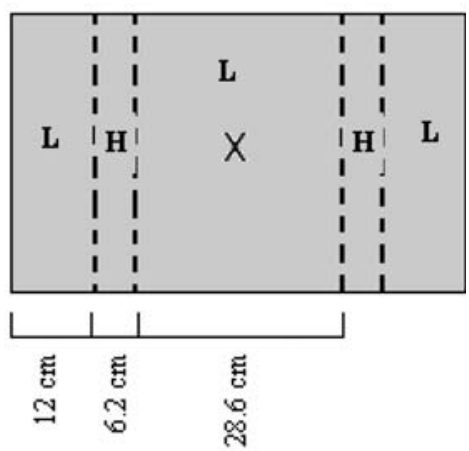

Homogeneous soil treatment

Figure 1. Diagram of a fen mesocosm with patchy (left) and homogeneous nutrient distributions (right). 
To test the effects of physiological integration on plant performance, we compared treatments with connected rhizomes and with severed rhizomes. For both connected and severed treatments, every week we gently probed into the soil to locate connections between ramets and recorded which parent ramet produced each new daughter ramet. For the severed treatments, we then used scissors to sever each rhizome midway between the new ramet and its parent ramet. We only severed rhizomes between parent ramets and daughter ramets that had attained a height of at least $10 \mathrm{~cm}$ during the previous week. Rhizomes in connected treatments were left intact.

The homogeneous and patchy soil treatments were fully crossed with the severing treatments, so that we could observe any interactions between soil resource distribution and physiological integration. Each experimental block included all four treatments; therefore, each treatment was replicated a total of 5-times. Treatments were ordered randomly within a block. It is important to note that we included the homogeneous-severed treatment in our experimental design. When compared to the homogeneous-connected treatment, where we predicted that integration would have no effect, the homogeneous-severed treatment allowed us to identify any reduction in growth caused by the severing process itself. Thus, we could separate an effect of severing damage from an effect of lack of integration.

At the end of August 2001, we measured ramet heights and numbers of ramets for each patch type in the patchy soil treatments and over the entire tub in the homogeneous soil treatments. We then allowed all ramets to grow undisturbed with no further severing for an additional 12 months, so that we could observe the long-term effects of initial lack of integration. In late August 2002 we harvested the aboveground part of all ramets by cutting them off at the soil surface. For both soil treatments, we recorded the within-tub physical location of each ramet as either high-nutrient or low-nutrient (Figure 1). For homogeneous soil treatments, we designated a ramet 'high-nutrient' if its location in the tub fell within one of the $46 \times 6.2 \mathrm{~cm}$ bands that corresponded to the location of the peat bands in the patchy treatment, even though all ramets on homogeneous soil had access to the same medium level of nutrients, regardless of physical location (Figure 1). We designated all other ramets in the homogeneous treatment 'low-nutrient'. Separating ramets by physical location in the homogeneous treatment allowed direct comparison between ramet placement on a substrate with a homogeneous nutrient distribution and ramet placement on a substrate containing pure high-nutrient and low-nutrient patches.

We dried all harvested ramets at $65^{\circ} \mathrm{C}$ to a constant mass and weighed total shoot mass of ramets in each patch type in each tub.

\section{Response variables}

To obtain biomass estimates for the first year in this experiment, we used regression equations of shoot biomass on shoot height from clones grown in the 80:20 homogeneous mixture of marl and peat (connected treatment: $\ln$ (biomass) $=-9.89+1.41 \ln$ (height); $R^{2}=0.95, p<0.001$, d.f. $=1,22$; severed treatment: $\ln$ (biomass) $=-9.29+1.30 \quad \ln$ (height); $R^{2}=0.92, p<0.001$, d.f. $=1,22$ ). These estimates were similar to the actual biomass of a subsample of $S$. pungens clones that were harvested from the same severing and soil treatment combinations at the end of 2001 for a separate study.

From these data on total number and biomass of ramets per tub in each year, the following additional response variables were calculated: mean biomass per ramet, both overall and for each patch type, where mean biomass per ramet in patch type $i=($ total biomass in patch type $i) /$ (number of ramets in patch type $i$ ); per capita clonal growth rates, where 2001 growth rate $=\ln$ (total biomass at end of 2001/total biomass 1 week after planting) and 2002 growth rate $=1$ n (total biomass at end of 2002/total biomass at end of 2001), and proportion of ramets in each patch type $i=$ total number of ramets in patch type $i) /($ total number of ramets per tub). We found no ramets recruited from seeds during this experiment. In order to study foraging behavior in the first year, we had to estimate the proportion of ramets that would be located in the 'highnutrient' patches of homogeneous soil, because we did not record separately the number of ramets by physical location in this treatment. To do this, we assumed that ramets in the homogeneous soil treatments were distributed evenly over the entire tub so that the expected proportion was 
simply the proportion of area of these patches $(=0.20)$.

\section{Data analysis}

We performed Analyses of Variance (ANOVAs) with SYSTAT version 10, using a two-way factorial design (SYSTAT 2000). To determine the effects of physiological integration on the growth of an entire clone in both homogeneous and heterogeneous environments, we tested for dependence of total biomass, mean ramet size, total number of ramets, and per capita growth rate on severing treatment, soil treatment, and their interaction for each year separately. To determine the effects of environmental heterogeneity on the placement of biomass and to determine whether physiological integration had any effect on foraging ability, we tested for dependence of the proportion of ramets and of biomass in high-nutrient patches on soil treatment and severing treatment. To verify the assumptions of the ANOVAs, we performed Kolmogorov-Smirnov tests with Lilliefors probability and examined plots of model residuals versus estimated values; in no cases did the data significantly deviate from the assumption of homogeneous variances. Three significant outliers were deleted from all analyses (identified by significant studentized residuals, Systat 2000).

\section{Results}

Effects of severing and environmental heterogeneity on biomass of entire clones

As predicted, severing significantly decreased total biomass of Schoenoplectus pungens in year one $(F=8.38, \quad p<0.01)$, but this effect disappeared the year after severing treatments stopped $(F=2.41, \quad p>0.1) \quad$ (Figure $2 \mathrm{a}$ and b). Also, severing decreased individual ramet biomass both in year one $(F=40.63, p<0.0001)$ and the year after severing stopped $(F=7.95, \quad p<0.05)$, although the magnitude of the effect decreased in the second year (Figure 2c and d). Severing had no significant effect on the number of ramets present in year one $(F=0.34, p>0.5)$ or in year two $(F=2.97, p>0.1)$ (Figure 2e and f). Severing decreased per capita growth rate in year one
$(F=10.64, \quad p<0.01 ;$ Figure $2 \mathrm{~g})$, but increased growth rate in the second year $(F=8.87$, $p<0.05$ ), although, for both treatments, the growth rate was lower in year two than in year one (Figure 2h).

Contrary to our predictions, soil treatment had no significant effect on any measure of $S$. pungens growth in year one, nor did it interact in any way with the severing treatment $(p>0.4$ in all cases; Figure 2a, c, d, e, f and g). However, by the end of year two, total biomass was significantly higher on homogeneous soil $(F=6.41, p<0.05)$, regardless of severing treatment and a similar, but nonsignificant trend was evident in the total number of ramets $(F=4.43, p=0.055)$ (Figure $2 \mathrm{~b}$ and $\mathrm{f}$ ).

\section{Effects of environmental heterogeneity on foraging behavior}

As predicted, $S$. pungens exhibited plastic foraging behavior at the level of the entire clone. At the end of year one, clones with connected rhizomes appeared to concentrate more ramets in the highnutrient locations of the patchy soil treatment than expected given an even distribution of ramets (Figure 3a), although the $95 \%$ confidence interval of the observed values overlaps with the expected values. At the end of year two, clones concentrated more ramets in high-nutrient patches when they were grown on patchy soil (i.e., when the "highnutrient' patches contained pure peat) than when they were grown on homogeneous soil $(F=4.88$, $p<0.05$; Figure 3b). A similar trend was evident for biomass (Figure 3c), but was not statistically significant $(F=4.14, p=0.059)$.

\section{Effects of severing on foraging behavior}

In the first year, there did appear to be an interaction between physiological integration and foraging ability of $S$. pungens, as we predicted, although this cannot be tested statistically. Contrary to our prediction, however, connections between ramets actually increased the amount of biomass clones placed in high-nutrient patches, i.e., integration increased rather than decreased plasticity due to foraging (Figure 3a). In the year after severing stopped, this treatment had no effect on the proportion of ramets $(F=0.07, p>0.5$; 

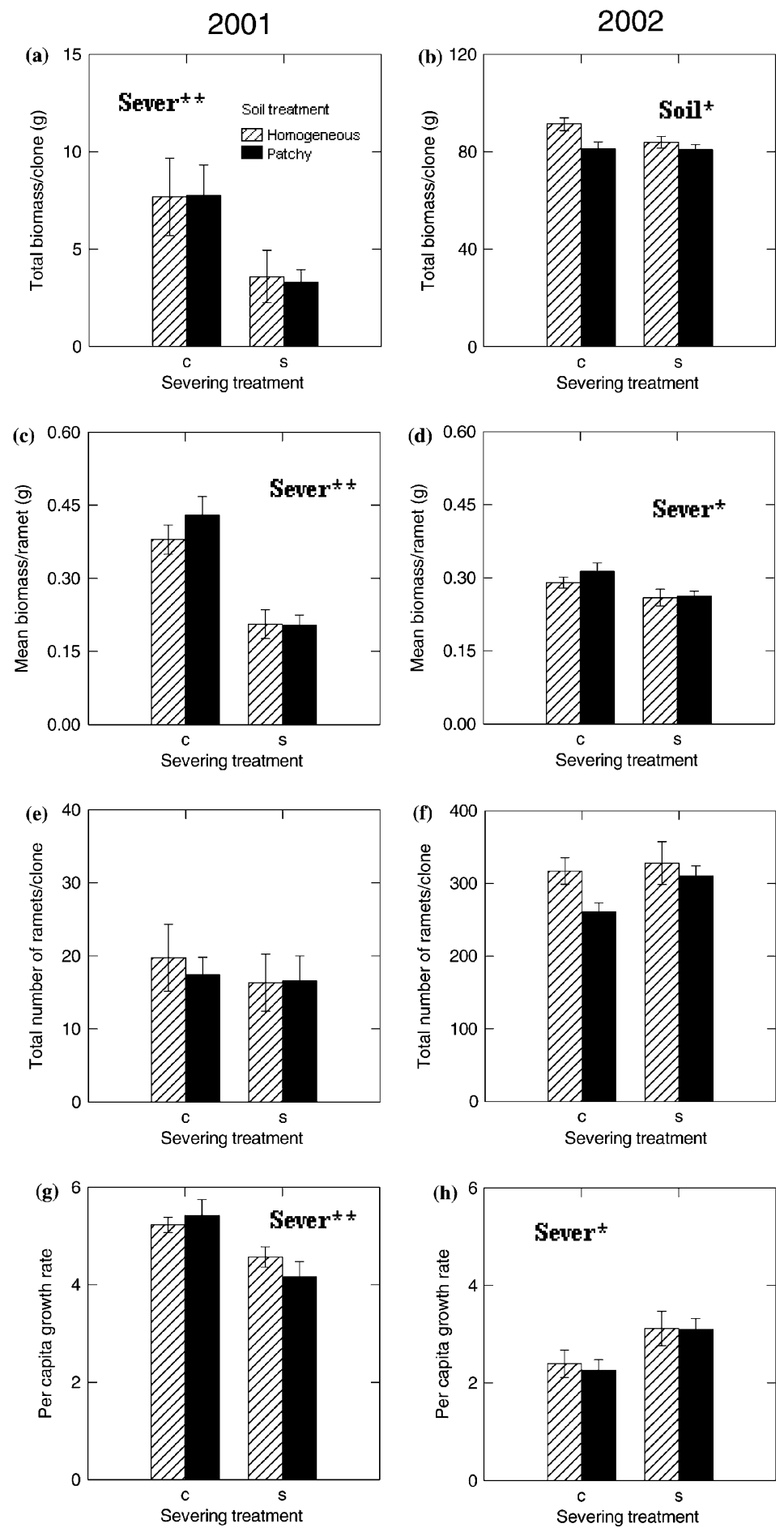

Figure 2. Effects of severing ( $\mathrm{c}=$ connected; $\mathrm{s}=$ severed $)$ and environmental heterogeneity on mean $\pm \mathrm{SE}$ of measures of clonal growth in 2001 (left column) and 2002 (right column). Also shown are significant main effects and interactions from two-way factorial ANOVAs, ${ }^{*} p<0.05,{ }^{* *} p<0.01$. (a and b) Total biomass per tub in 2001; (c and d) Mean biomass per ramet; (e and f) Total number of ramets per tub, (g and h) Growth rate in total biomass. 

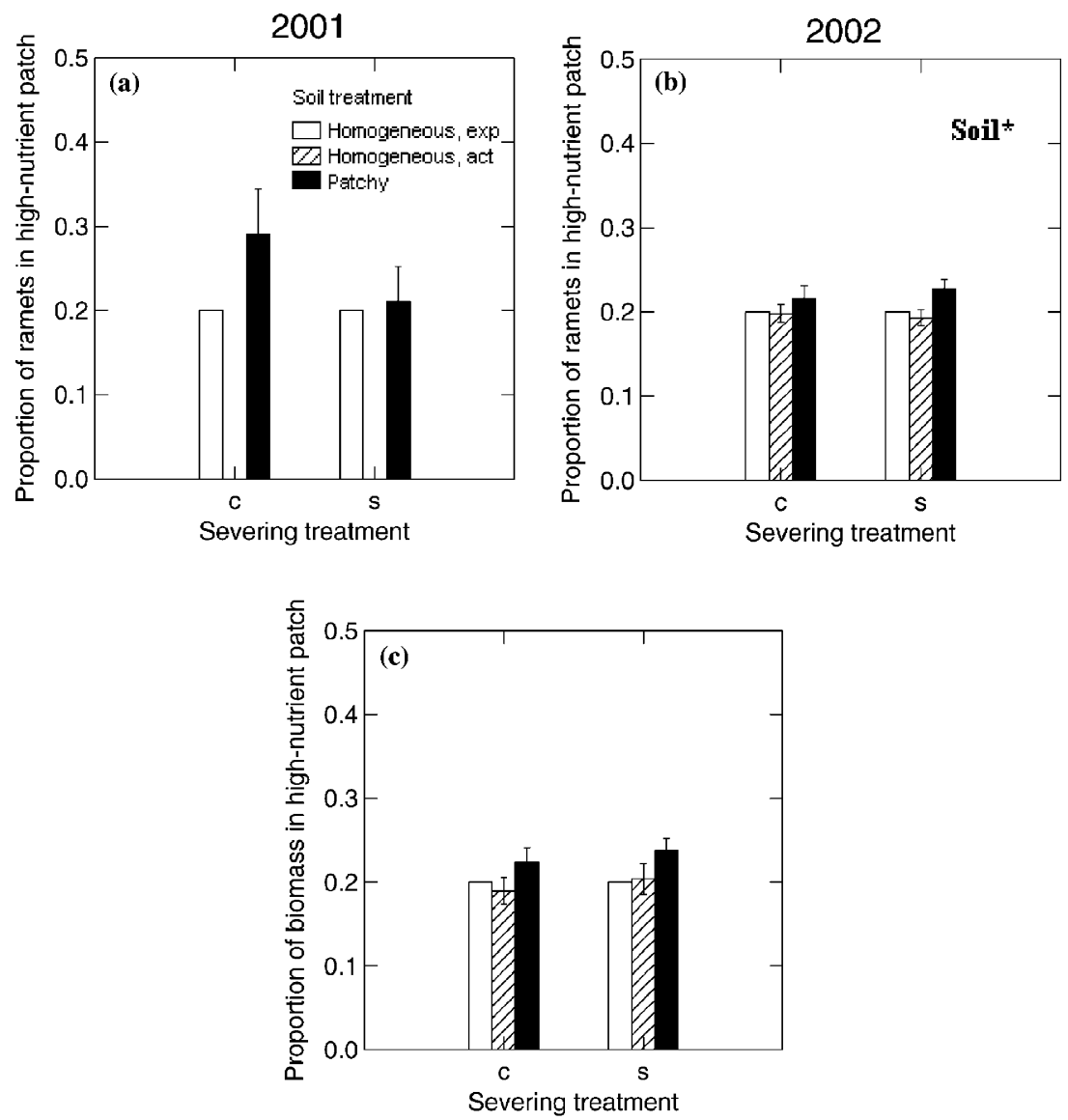

Figure 3. Effects of severing $(\mathrm{c}=$ connected; $\mathrm{s}=$ severed $)$ and environmental heterogeneity on mean $\pm \mathrm{SE}$ proportion of ramets in 'high-nutrient' patch locations in 2001 and 2002. exp = expected value in the homogeneous treatment, assuming an even distribution of ramets throughout a tub (no error estimate available). act $=$ actual values in the homogeneous soil treatment. Also shown are significant main effects and interactions from two-way factorial ANOVAs, ${ }^{*} p<0.05$. (a and b) Proportion of total ramets in "highnutrient' patches; (c) Proportion of total biomass in 'high-nutrient' patches.

Figure $3 \mathrm{~b})$ or of biomass $(F=0.72, \quad p>0.1$; (Figure 3c) in peat patches.

\section{Discussion}

Effects of severing and environmental heterogeneity on growth of entire clone

We found no evidence to support the hypothesis that physiological integration would increase the overall growth of Schoenoplectus pungens on heterogeneous soil. We did see significant negative severing effects on total biomass and per capita growth rate in year one and on mean ramet biomass in years one and two. However, this negative effect of severing occurred on homogeneous soil as well as heterogeneous soil, even though all ramets in homogeneous soil treatments should have had access to the same amount of nutrients regardless of severing. Therefore, the reduction in growth in severed treatments was most likely due to severing damage. Although there may also have been some negative impact of reduced integration in the severing treatment that was masked by the damage effect, there was no significant interaction of the severing treatments with the soil treatments, suggesting any such impact of reduced integration was minimal. In the second year, the damage effect disappeared, but previous connections between ramets did not affect accumulation of total biomass on either homogeneous or heterogeneous soil. These results suggest that there is no long-term benefit of physiological integration in S. pungens. 
Interestingly, individual ramet biomass was smaller in severed treatments than in connected treatments (regardless of soil treatment) the year after severing was discontinued, suggesting that damage decreased the ability of rhizomes to store nutrients needed to produce sizable ramets in subsequent growing seasons. Few authors investigating physiological integration have observed a large damage effect when using severing experiments. For example, Charpentier et al. (1998) found that when severed, Scirpus maritimus clones actually produced more ramets than when left intact, although individual ramets were smaller. Wijesinghe and Handel (1994) saw effects of severing Potentilla simplex in heterogeneous habitats, but not in homogeneous habitats, ruling out a consistent damage effect. Given the nature of S. pungens rhizomes - they are thin and delicate - this species may be comparatively more susceptible to physical damage than previously studied species.

Contrary to our prediction that the positive effects of physiological integration would be most pronounced in a heterogeneous environment, total biomass was higher on homogeneous soil than on heterogeneous soil and there was a trend for clones to grow more ramets on homogeneous soil than on patchy soil, regardless of severing treatment. Ramets in the patchy treatment were initially planted in pure marl soil, where they would have had access to fewer nutrients than ramets initially planted in homogeneous soil. Furthermore, most evidence suggests that transport of nutrients in clonal plants is mainly acropetal (Noble and Marshall 1983; Slade and Hutchings 1987; Evans 1988; Price et al. 1992; D’Hertefeldt and Jónsdóttir 1999). Even in connected treatments, the ramets initially planted in pure marl soil would have had little to contribute to subsequent ramet generations, and would not have profited from ramets in peat patches. This argument suggests that clones on homogeneous soil had a growth advantage from the beginning. On the other hand, this phenomenon did not manifest itself until the second year. Why this should be is unknown, as other experiments have found differences in growth between clones initially planted in favorable conditions and clones initially planted in unfavorable conditions after only a few months (Noble and Marshall 1983; Slade and Hutchings 1987; Evans 1988; Stuefer et al. 1994). Future research should consider the importance of initial environmental conditions to test whether clones with ramets initially located in nutrient-rich soil fare better over the long run (i.e., more than one year) than those with ramets initially located in nutrient-poor soil. Effects of initial conditions in heterogeneous environments may be particularly important for genets establishing from seed.

It is also possible that we did not see the expected response to environmental heterogeneity due to the size of patches in our mesocosms. Wijesinghe and Hutchings (1999) found that clonal growth of Glechoma hederacea was greater when patches were $625 \mathrm{~cm}^{2}$ in area than when patches were $156 \mathrm{~cm}^{2}$. In a separate study (1997), they found that out of a range of patch sizes from $39 \mathrm{~cm}^{2}$ to $1250 \mathrm{~cm}^{2}$, growth was greatest at $625 \mathrm{~cm}^{2}$. Perhaps the patches we created, at $285 \mathrm{~cm}^{2}$ each, were too small for $S$. pungens to take advantage of the heterogeneity at the clone level. Indeed, the fact that the tubs were completely filled with ramets by the end of the two years suggests that the clones may have been limited by space overall. This would also explain the increased second year growth rate of severed clones relative to connected clones: the connected clones had already had a chance to fill the pots, and the severed clones had to 'catch up' after the damage inflicted by severing.

\section{Effects of environmental heterogeneity on foraging behavior}

Clones placed more ramets in pure peat patches than in equivalent patches of homogeneous soil. This result is consistent with our hypothesis that Schoenoplectus pungens would exhibit clone-level foraging behavior by concentrating ramets in highnutrient patches. We did not measure the length or branching frequency of rhizomes, so we cannot comment on the mechanism by which clones concentrated ramets. Nor can we draw any conclusions about the presence of the morphological plasticity in roots or shoots of individual ramets that is necessary for ramet-level foraging within clones and characteristic of a division of labor scenario. We did not measure root biomass, even though roots are the critical foraging organs of each ramet in nutrient-limited environments (de Kroon and Hutchings 1995; Wijesinghe and Hutchings 1997, 1999; Dong and Alaten 1999). 


\section{Effects of severing on foraging behavior}

In the first year of the experiment, physiological integration and plastic foraging behavior appeared to interact. Contrary to what we predicted, physiological integration seemed to increase foraging ability, because only in connected treatments was the number of ramets invested in high-nutrient patches greater than the number invested in lownutrient patches. Another possibility is that severing affected not only clone growth, but also the capacity for plastic growth responses in severed clones. Given the drastic effects of severing damage on the overall growth of clones, this explanation seems more likely.

In the second year of the experiment, clones with severed rhizomes concentrated the same proportion of biomass in peat patches as clones with connected rhizomes, so apparently there was no link between widespread physiological integration and the ability of $S$. pungens to forage after two growing seasons. Therefore it seems likely that more ramets grew in peat because individual parent ramets responded to the conditions of their own microsite and produced daughter ramets accordingly. Local responses of independent but nonetheless integrated clone-parts are common, and may be the rule for some species (Hutchings and Mogie 1990; Price et al. 1992; Hutchings and Price 1993; Wijesinghe 1994). In the present study, we allowed daughter ramets to become established and potentially independent before they were severed from parent ramets. Thus, our result does not preclude an effect of integration between parents and daughters at the earliest stages of daughter development and establishment.

\section{Implications for life history strategy}

S. pungens exhibits a growth form characterized by relatively widely spaced ramets along spreading rhizomes. The apparent lack of physiological integration observed in S. pungens may be related to this overall clone morphology. Species that have the spreading 'guerrilla' growth form exhibit less physiological integration than do species with a compact 'phalanx' growth form (Schmid and Bazzaz 1987; Hutchings and Mogie 1990; Wilhalm 1995; but also see D'Hertefeldt and Jónsdóttir 1999; D'Hertefeldt and Falkengren-Grerup 2002).
Extensive integration decreases the speed with which a clone can spread out and take advantage of favorable habitat patches, because ramets in favorable patches have to compromise their own growth by providing support to ramets in unfavorable patches, and ramets in unfavorable patches are able to proliferate if they receive support from other ramets (Hutchings and Mogie 1990). Thus, the amount of biomass a clone invests in unfavorable habitat patches is not minimized, which is contradictory to an optimal foraging strategy. Research suggests that in some species there exists a 'cutting-off' point, a threshold after which daughter ramets no longer receive support from parent ramets, and that this may prevent integrated clones from wasting their resources in poor patches (Jónsdóttir and Callaghan 1989). However, it is unknown whether this control of integration would or could evolve in a system that wasn't already highly integrated. On the other hand, it may be pointless for a highly-integrated clone with a compact growth form to forage, because all ramets are likely to fall within a short distance of each other. In this case, strong physiological integration may be important because it minimizes competition between the closely-spaced ramets (Schmid and Bazzaz 1987; Hutchings and Mogie 1990). Also, as stated previously, strong integration is often cited as an advantage in temporally unpredictible environments, where the costs of clone-level morphological plasticity may be prohibitively high (Hutchings and de Kroon 1994). The fen environment is not one characterized by frequent, unpredictable disturbances (Hershock 2002).

Many studies document the positive effects of physiological integration on clonal growth in heterogeneous environments (Alpert and Mooney 1986; Evans 1988; Alpert 1991; Evans and Whitney 1992; Stuefer et al. 1994; Wijesinghe and Handel 1994; Dong and Alaten 1999). Although extensive integration has been documented for some species with guerrilla growth forms (Jónsdóttir and Watson 1997; D'Hertefeldt and Jónsdóttir 1999; D'Hertefeldt and FalkengrenGrerup 2002), guerrilla species with low integration, but high allocation to rhizome growth as well as clone-level foraging may also exhibit high relative fitness in heterogeneous environments. For instance, in our mesocosms, $S$. pungens grew extremely rapidly due to high allocation of 
biomass to rhizomes, so that by the end of two growing seasons each mesocosm was entirely filled with ramets (average density $=1006$ ramets $/ \mathrm{m}^{2}$ ). We also found that $S$. pungens forages at the clonelevel in heterogeneous environments, although this did not depend on physiological integration. Thus, the life history strategy of $S$. pungens may be characterized by rapid horizontal growth accompanied by clone-level foraging behavior and ramet independence, at least after the establishment stage. This clonal life history strategy could allow genets to rapidly colonize spatially heterogeneous habitats, maximizing the number of ramets that colonize resource-rich patches.

\section{Conclusions}

We found no evidence to support the hypotheses that physiological integration provides the greatest benefit in a heterogeneous environment or that physiological integration benefits clonal growth of Schoenoplectus pungens over more than one growing season. We did find evidence to support the hypothesis that clones exhibit plastic foraging behavior via the concentration of ramets in nutrient-rich patches. Additional research is required to fully understand the mechanisms by which physiological integration influences the foraging behavior of clonal plants in heterogeneous environments.

\section{Acknowledgements}

This research was funded by a collaborative grant from the National Science Foundation (DEB9974284 to L. Gough and DEB99-74296 to D.E. Goldberg). We thank MIDNR for our research permits and the University of Michigan Matthaei Botanical Gardens for the use of their facilities and their continued support of our fen plant ecology research. We also thank Josh Kammers, Radka Wildova, and Nanci Ross for assisting with this research.

\section{References}

Alpert P. 1991. Nitrogen sharing among ramets increases clonal growth in Fragaria chiloensis. Ecology 72: 69-80.
Alpert P. 1999. Effects of clonal integration on plant plasticity in Fragaria chiloensis. Plant Ecol. 141: 99-106.

Alpert P. and Mooney H.A. 1986. Resource sharing among ramets in the clonal herb, Fragaria chiloensis. Oecologia 70: 227-233.

Amon J.P., Thompson C.A., Carpenter Q.J. and Miner J. 2002. Temperate zone fens of the glaciated Midwestern USA. Wetlands 22: 301-317.

Charpentier A., Mesleard F. and Thompson J.D. 1998. The effects of rhizome severing on the clonal growth and clonal architecture of Scirpus maritimus. Oikos 83: 107-116.

de Kroon H. and Hutchings M.J. 1995. Morphological plasticity in clonal plants: the foraging concept reconsidered. J. Ecol. 83: 143-152.

de Kroon H. and Schieving F. 1990. Resource partitioning in relation to clonal growth strategy. In: van Groenendael J. and de Kroon H. (eds), Clonal Growth in Plants: Regulation and Function. SPB Academic Publishers, The Hague, pp. 113-130.

de Kroon H. and van Groenendael J. (eds) 1997. The Ecology and Evolution of Clonal Plants. Bachhuys Publishers, Leiden, The Netherlands.

D'Hertefeldt T. and Falkengren-Grerup U. 2002. Extensive physiological integration in Carex arenaria and Carex disticha in relation to potassium and water availability. New Phyotol. 156: 469-477.

D’Hertefeldt T. and Jónsdóttir I. 1999. Extensive physiological integration in intact clonal systems of Carex arenaria. J. Ecol. 87: 258-264.

Dong M. and Alaten B. 1999. Clonal plasticity in response to rhizome severing and heterogeneous resource supply in the rhizomatous grass Psammochloa villosa in an Inner Mongolian dune, China. Plant Ecol. 141: 53-58.

Evans J.P. 1988. Nitrogen translocation in a clonal dune perennial, Hydrocotyle bonariensis. Oecologia 77: 64-68.

Evans J.P. and Cain M.L. 1995. A spatially explicit test of foraging behavior in a clonal plant. Ecology 76: 1147-1155.

Evans J.P. and Whitney S. 1992. Clonal integration across a salt gradient by a nonhalophyte, Hydrocotyle bonariensis (Apiaceae). Am. J. Bot. 79: 1344-1347.

Hershock C. 2002. Plant community structure in calcareous fens: effects of competition, soil environment, and clonal architecture. Ph.D. Thesis. University of Michigan, Ann Arbor, MI.

Hutchings M.J. and de Kroon H. 1994. Foraging in plants: The role of morphological plasticity in resource acquisition. In: Begon M. and Fitter A.H. (eds), Advances in Ecological Research v. 25. Academic Press, New York, pp. 159-238.

Hutchings M.J. and Mogie M. 1990. The spatial structure of clonal plants: control and consequences. In: van Groenendael J. and de Kroon H. (eds), Clonal Growth in Plants: Regulation and Function. SPB Academic Publishers, The Hague, pp. $57-76$.

Hutchings M.J. and Price E.A.C. 1993. Does physiological integration enable clonal herbs to integrate the effects of environmental heterogeneity? Plant Species Biol. 8: 95-105.

Jerling L. 1988. Clone dynamics, population dynamics and vegetation pattern of Glaux maritima on a Baltic sea shore meadow. Vegetatio 74: 171-185.

Jónsdóttir I.S. and Callaghan T.V. 1989. Localized defoliation stress and the movement of C14-photoassimilates between tillers of C. bigelowii. Oikos 54: 211-219. 
Jónsdóttir I.S. and Watson M.A. 1997. Extensive physiological integration: an adaptive trait in resource-poor environments. In: de Kroon H. and van Groenendael J. (eds), The Ecology and Evolution of Clonal Plants. Backhuys Publishers, Leiden, pp. 109-136.

Lovett Doust L. 1981. Population dynamics and local specialization in a clonal perennial (Ranunuculus repens): I. the dynamics of ramets in contrasting habitats. J. Ecol. 69: 743755 .

Magee D.W. 1981. Freshwater Wetlands: A Guide to Common Indicator Plants of the Northeast. University of Massachusetts Press, Amherst.

Noble J.C. and Marshall C. 1983. The population biology of plants with clonal growth: the nutrient strategy and modular physiology of Carex arenaria. J. Ecol. 71: 865-877.

Price E.A.C., Marshall C. and Hutchings M.J. 1992. Studies of growth in the clonal herb Glechoma hederacea. I. Patterns of physiological integration. J. Ecol. 80: 25-38.

Schmid B. and Bazzaz F.A. 1987. Clonal integration and population structure in perennials: effects of severing rhizome connections. Ecology 68: 2016-2022.

Slade A.J. and Hutchings M.J. 1987. Clonal integration and plasticity in foraging behaviour in Glechoma hederacea. J. Ecol. 75: 1023-1036.

Stuefer J.F., During H.J. and de Kroon H. 1994. High benefits of clonal integration in two stoloniferous species, in response to heterogeneous light environments. J. Ecol. 82: 511-518.
Stuefer J.F., De Kroon H. and During H.J. 1996. Exploitation of environmental heterogeneity by spatial division of labour in a clonal plant. Functional Ecol. 10: 328-334.

Sutherland W.J. and Stillman R.A. 1988. The foraging tactics of plants. Oikos 52: 239-244.

SYSTAT. 2000. SYSTAT Version 10. SPSS Inc, Chicago.

Voss E.G. 1972. Michigan Flora; A Guide to the Identification and Occurrence of the Native and Naturalized Seed Plants of the State. Cranbrook Institute of Science, Bloomfield Hills, Michigan.

Wilhalm T. 1995. A comparative study of clonal fragmentation in tussock-forming grasses. Abstracta Botanica 19: 51-60.

Wijesinghe and D.K. 1994. Temporal and structural components of ramet independence in the clonal perennial herb, Potentilla simplex. J. Ecol. 82: 13-20.

Wijesinghe D.K. and Handel S.N. 1994. Advantages of clonal growth in heterogeneous habitats: an experiment with Potentilla simplex. J. Ecol. 82: 495-502.

Wijesinghe D.K. and Hutchings M.J. 1997. The effects of spatial scale of environmental heterogeneity on the growth of a clonal plant: an experimental study with Glechoma hederacea. J. Ecol. 85: 17-28.

Wijesinghe D.K. and Hutchings M.J. 1999. The effects of environmental heterogeneity on the performance of Glechoma hederacea: the interactions between patch contrast and patch scale. J. Ecol. 87: 860-872. 